\title{
Long-Term Oxygen Therapy in COPD: evidences and open questions of current indications
}

\author{
A. Corrado, T. Renda, S. Bertini
}

\begin{abstract}
Long-Term Oxygen Therapy in COPD: evidences and open questions of current indications. A. Corrado, T. Renda, S. Bertini.

Long term oxygen therapy (LTOT) has been shown to improve the survival rate in Chronic Obstructive Pulmonary Disease (COPD) patients with severe resting hypoxemia by NOTT and MRC studies, published more than 25 years ago. The improved survival was found in patients who received oxygen for more than $\mathbf{1 5}$ hours/day. The effectiveness of LTOT has been documented only in stable COPD patients with severe chronic hypoxemia at rest $\left(\mathrm{PaO}_{2}<55 \mathrm{mmHg}(7.3 \mathrm{kPa})\right.$ or $\mathrm{PaO}_{2}$ ranging from 56 to $59 \mathrm{mmHg}(7.4-7.8 \mathrm{kPa})$ in presence of signs of Cor Pulmonale, hematocrit $>55 \%$. In fact no evidence supports the use of LTOT in COPD patients with moderate hypoxemia $\left(55<\mathrm{PaO}_{2}<65 \mathrm{mmHg}\right)$, and in those with decreased oxygen saturation $\left(\mathrm{SO}_{2}<90 \%\right)$ during exercise or sleep.
\end{abstract}

Furthermore, it is generally accepted without evidence that LTOT in clinical practice is warranted in other forms of chronic respiratory failure not due to COPD when arterial blood gas criteria match those established for COPD patients. The prescription of oxygen in these circumstances, as for unstable patients, increases the number of patients receiving supplemental oxygen and the related costs. Comorbidities are likely to affect both prognosis and health outcomes in COPD patients, but at the moment we do not know if LTOT in these patients with complex chronic diseases and mild-moderate hypoxemia could be of any use. For these reasons a critical revision of the actual guide lines indications for LTOT in order to optimise effectiveness and costs, and future research in the areas that have not previously been addressed by NOTT and MRC studies, are mandatory.

Monaldi Arch Chest Dis 2010; 73: 1, 34-43.

Keywords: Long-Term Oxygen Therapy, COPD, Guidelines.

Terapia Intensiva Pneumologica, Azienda Ospedaliera Universitaria Careggi Firenze, Italy.

Correspondence: Dr Antonio Corrado, Terapia Intensiva Pneumologica-Fisiopatologia Toracica, Dipartimento specialità medicochirurgiche, Careggi Hospital, Padiglione Nuovo San Luca, Via di San Luca, Firenze, Italy; e-mail: acorrado@qubisoft.it; corradoa@aou-careggi.toscana.it

\section{Introduction}

Oxygen as a therapeutic agent was introduced in clinical practice about 70 years ago. It has been reported [1] that in the USA close to 800,000 patients receive long-term oxygen therapy (LTOT) at a cost of approximately $\$ 1.8$ billion annually and that [2] worldwide, several hundred of thousands of patients receive LTOT, following the recommendation of international documents [3-5].

It has been estimated that in Italy about 50 60,000 of patients receive LTOT with a global burden for the national health system (Servizio Sanitario Nazionale, SSN) amounting to about Euro 250,000,000/year. The large numbers of patients receiving supplemental oxygen as treatment and the high costs incurred in providing oxygen therapy is a crucial problem for the National Health Systems worldwide which obliges the scientific community to carry out a critical revision of the actual indications for LTOT as well as the effects of LTOT on survival and other outcomes. The evidence supporting this increased use of oxygen therapy and its actual indications are based on two landmark, prospective and ran- domised clinical trials published more than 25 years ago $[6,7]$. These studies showed that stable COPD patients, recruited according to pre-established inclusion criteria, live longer when they receive domiciliary LTOT for more than 15 hours/day. The stability of underlying chronic disease before commencing LTOT is crucial. In fact many COPD patients are prescribed oxygen therapy because they are hypoxemic at discharge from hospital after exacerbation of an underlying respiratory disease, despite an absence of data to support short-term or longer term benefits of oxygen therapy [8]. After acute exacerbations of COPD approximately $30-38 \%$ [9, 10] of patients improved $\mathrm{PaO}_{2}$ values merely by optimising medical management to the extent that they no longer fulfilled the selection criteria for LTOT. It has been reported, that reassessment of the indication for LTOT after some months of clinical stability reduced significantly the number of patients who would be eligible for LTOT soon after an episode of exacerbation [11]. In order to optimise oxygen use is advisable that patients should be reassessed, both at 3 months and at approximately one year after commencing oxygen therapy [11]. 
The effectiveness of LTOT in improving survival has been documented only in COPD patients with severe chronic hypoxemia $\left(\mathrm{PaO}_{2}\right.$ less than 55 $\mathrm{mmHg}(7.3 \mathrm{kPa})$ or $\mathrm{PaO}_{2}$ ranging from 56 to 59 $\mathrm{mmHg}(7.4-7.8 \mathrm{kPa})$ in presence of signs of cor pulmonale, hematocrit $>55 \%$ ). The recommendations for LTOT have been subsequently extended, albeit without solid evidence, to COPD patients with $\mathrm{PaO}_{2}>60 \mathrm{mmHg}$ at rest with decreased oxygen saturation during exercise or sleep $[4,8,12]$.

Furthermore, it is generally accepted without evidence that LTOT in clinical practice is warranted in other forms of chronic respiratory failure such as pulmonary fibrosis, kyphoscoliosis, cystic fibrosis when arterial blood gas criteria are similar to those established for COPD patients. This aspect may contribute, albeit marginally, to the increasing use and cost of oxygen.

In light of all these considerations and given the increasing cost of therapy for COPD $[13,14]$ it is clear that a reassessment of evidence supporting the extensive prescription of LTOT is needed, particularly for COPD patients with co-morbidities, mildmoderate hypoxemia, exercise and sleep desaturation. Therefore, the aim of this review is to address the open questions regarding LTOT prescription and possible future clinical research in this field.

\section{Hypoxemia: Physiologic Consequences}

Hypoxemia induces several physiologic responses in order to maintain adequate oxygen delivery to the tissue but prolonged compensatory mechanism may have detrimental long-term effects $[7,6,15-17]$. If untreated, hypoxemia often progress to tissue hypoxia, which may result in adverse effects on vital organ function and in structural and permanent damage. Hypoxemia $\left(\mathrm{PaO}_{2}\right.$ below $55 \mathrm{mmHg}$ ) increases ventilatory drive in order to increase $\mathrm{PaO}_{2}$ values with a reduction of arterial levels of $\mathrm{PaCO}_{2}$. The negative consequence of this mechanism is an increase in difficulty breathing. Hypoxemia induces peripheral vascular beds dilatation with consequent increase in heart rate and cardiac output in order to improve oxygen delivery; the regional pulmonary vasoconstriction due to alveolar hypoxia tries to improve the ventilation perfusion matching. High levels of erythropoietin due to persistent hypoxemia with consequent erythrocytosis from one hand increases oxygen carrying capacity and in the other hand the hematologic viscosity. All these mechanisms can cause detrimental long-term effects such as pulmonary hypertension, right ventricular failure and polycythemia $[1,17]$.

\section{Oxygen Treatment}

Supplemental oxygen can reverse hypoxaemia and prevents tissue damages due to acute and chronic hypoxia. Oxygen therapy represents an essential part of treatment in the care of COPD patients with chronic respiratory failure.

The long term administration of oxygen improves life expectancy in these patients [6,7], functional and clinical outcomes such as pulmonary haemodinamics, cognitive function [6]. The mechanism by which oxygen use improves survival is not yet completely understood.

Several studies have attempted to find potential prognostic factors in patients receiving longterm oxygen therapy. These factors included age $[18,19]$, the severity of airway obstruction [20], the presence of pulmonary hypertension $[15,21]$, hypercapnia [7, 18, 19, 22].

In general, it has been reported that variables reflecting the severity of COPD, such as reduction of $\mathrm{PaO}_{2}$ or increased $\mathrm{PaCO}_{2}$ values, lower $\mathrm{FEV}_{1}$ and elevated mean pulmonary artery pressure correlate inversely with survival [18-24]. LTOT has also been shown to have a number of important physiological benefits, but data including healthrelated quality of life or reduction in disease exacerbations is very scarce.

\section{Effects of Long Term Oxygen Therapy on Mortality}

\section{Severe hypoxemia}

Early uncontrolled studies have shown a reduction in mortality in patients with COPD, cor pulmonale, and severe hypoxemia with the use of continuous oxygen therapy for some months $[25,26]$.

The data showing the effects of LTOT on survival and physiologic function in patients with severe COPD derived from two landmark controlled studies $[6,7]$. In the MRC trial survival was favourably influenced by oxygen use for at least 15 hours/day. At three years, mortality was $45.2 \%$ in the oxygen treated group and $66.7 \%$ in controls and appeared to be highest in the subgroup of patients who had highest $\mathrm{PaCO}_{2}$ and red cell mass at baseline. In the NOTT COT study patients with COPD were randomly allocated to receive either continuous (mean 17.7 hours/day) versus nocturnal oxygen therapy. Mortality for the nocturnal oxygen therapy group was significantly higher than that for the continuous oxygen therapy group (20.6\% at 12 months and $40.8 \%$ at 24 months vs $11.9 \%$ and 22.45 respectively). In table 1 the main characteristics and outcomes of the two studies are reported.

These studies are not fully comparable. Patients in the MRC study were more severe regarding resting hypercapnia and pulmonary hypertension. Furthermore, many patients in the MRC study continued to smoke even after enrolment into the trial, but no data has been reported in either study to ascertain whether smoking status or cessation affects the outcomes. Finally, the MRC study found no statistically significant impact of oxygen therapy including the sleeping hours versus no oxygen treatment on physiologic variables, whereas the NOTT study found a statistically significant decrease in pulmonary vascular resistance and hematocrit associated with continuous oxygen therapy. Despite the differences reported, these two prospective and controlled studies established that continuous oxygen therapy for more than 15 


\begin{tabular}{|c|c|c|}
\hline Study & $\begin{array}{l}\text { MRC } 1981 \\
\quad(\text { Ref. } 7)\end{array}$ & $\begin{array}{l}\text { NOTT } 1980 \\
\quad(\text { Ref. 6) }\end{array}$ \\
\hline Age (years) & $42-69$ & $>35$ \\
\hline Patients, $\mathbf{n}^{\circ}$ & 87 & 203 \\
\hline Study design & Randomised, Prospective, controlled & Randomised Prospective, controlled, not blinded \\
\hline Protocol & $\begin{array}{c}\mathrm{No} \mathrm{O}_{2} \text { vs }>15 \mathrm{Hrs} / \text { day } \\
\text { including the sleeping hours }\end{array}$ & nocturnal $\mathrm{O}_{2}$ vs continuous $\mathrm{O}_{2}$ \\
\hline $\mathbf{F E V}_{1}$ & $0.58-0.76 \mathrm{~L}$ & $29 \%$ predicted \\
\hline Female, \% & 24 & $20-23$ \\
\hline $\mathrm{PaO}_{2}, \mathrm{mmHg}$ & $49-51$ & 51 \\
\hline $\mathrm{PaCO}_{2}, \mathrm{mmHg}$ & $55-60$ & 43 \\
\hline PAPm, mmHg & $32-35$ & 30 \\
\hline Hours of $\mathrm{O}_{2} /$ die & 0 vs 15 & $12 \pm 2.5$ vs $17.7 \pm 4.8$ \\
\hline Smoking status & $25-52 \%$ & Not reported \\
\hline Outcomes & Mortality, $\mathrm{FEV}_{1}, \mathrm{FVC}, \mathrm{PaO}_{2}$ and $\mathrm{PaCO}_{2}$ & $\begin{array}{c}\text { Mortality, Quality of life } \\
\text { Cardiovascular parameters: } \\
\text { RAP, PAP, PWP, CI, SVI, PVR, RVSI }\end{array}$ \\
\hline $\begin{array}{l}\text { CI: cardiac index } \\
\text { pressure of oxyg } \\
\text { vascular resistanc } \\
\text { ventricular stroke }\end{array}$ & $\begin{array}{l}\text { orced Expiratory Volume in One Secon } \\
\text { arterial partial pressure of carbon dioxi } \\
\text { ulmonary wedge pressure; RAP: right at }\end{array}$ & $\begin{array}{l}\text { FVC: Forced vital capacity; } \mathrm{PaO}_{2} \text { : arterial par } \\
\text {;AP: pulmonary artery pressure; PVR: pulmon } \\
\text { al pressure; SVI: Stroke volume index; RVSI: ri }\end{array}$ \\
\hline
\end{tabular}

hours improved survival in severely hypoxemic COPD patients with elevated hematocrit, pulmonary artery pressure, and carbon dioxide retention and that continuous administration of oxygen is better than nocturnal alone. However, the causal relationship of these results is not yet well understood.

\section{Mild-Moderate Hypoxemia}

The role of oxygen in COPD patients who do not fulfil the criteria for continuous therapy is controversial. Gorecka et al [27] evaluated 135 patients with moderate hypoxemia $\left(\mathrm{PaO}_{2}, 56-65\right.$ $\mathrm{mmHg}$ at rest) and advanced airflow obstruction who were randomly allocated to receive no oxygen therapy or LTOT. The cumulative survival rates for the group at large were $88 \%$ at 1 year, $77 \%$ at 2 years, and $66 \%$ at 3 years. The authors found no significant difference in the survival rates between the two patient groups (treated with LTOT versus control therapy). Patients who were younger, with better lung function and higher body mass index showed better survival.

The results of this study could be related to the daily average use of oxygen for 13.5 hours in the study group. This duration may be inadequate, because in COPD patients on long term oxygen therapy it has been reported an increase in pulmonary vascular resistance when oxygen was stopped for as little for 3 hours [28].

Perhaps in a sub group of mild-moderate hypoxemic COPD patients with other conditions such as pulmonary hypertension, low body mass index, poor exercise capability, frequent exacerbations, or comorbid cardiac disease, LTOT should be advantageous in term of survival but no evidence has yet been reported [29].

\section{Effects of Long Term Oxygen Therapy on Functional and Clinical Outcomes}

\section{Pulmonary Hemodynamics}

Pulmonary hypertension $(\mathrm{PH})$, a common complication of severe COPD and chronic hypoxemia, is associated with increased mortality [21, $30,31]$, exacerbation rate and length of hospital stay, independent of the degree of airflow limitation [32]. LTOT is a proven therapy for chronic hypoxemic COPD with pulmonary hypertension $[6$, $7,15]$.

However, it has been suspected, but not clearly demonstrated, that the increased life expectancy was due to the improvement of pulmonary haemodynamics. It is estimated that $\geq 20 \%$ of patients with advanced COPD have pulmonary hypertension which occurs as mild to moderate but it may 
be severe and could be observed without severe airflow limitation [33, 34]. The latter which occurs in less than $5 \%$ of COPD patients [35] has been defined, in a recent study, as "out of proportion of pulmonary hypertension" [33]. These patients frequently exhibit a distinctive clinical pattern which shares similarities with other pulmonary vasculopathies, such as idiopathic pulmonary hypertension [33]. This suggests that other factors such as inflammation, remodelling of pulmonary vessels, in addition to alveolar hypoxia, contribute to the development of different patterns of PH in COPD. Currently there are no studies which emphasise the effectiveness of LTOT in "out of proportion PH" COPD patients.

Vasodilators with different mechanism of action have been employed to treat $\mathrm{PH}$ due to vasoconstriction, these drugs were tested mainly in idiopathic PH. A recent controlled trial has reported that a 3 months period of treatment with a combination of pulsed inhalation of nitric oxide (NO) and oxygen leads to sustained improvement in pulmonary haemodinamics in severe COPD patients with secondary pulmonary hypertension compared with oxygen treatment alone [36]. The addition of oxygen to NO further prevents hypoxaemia, but it remains to be determined whether pulsed NO/oxygen treatment will lead to an improvement of survival in these patients.

Further studies are required to determine the causal relationship of long-term oxygen administration on pulmonary hemodynamics and mortality in COPD patients.

\section{Hematocrit}

Haemoglobin levels in COPD patients reflect the balance between the stimulation and the depression of erythropoiesis induced by hypoxia and chronic inflammation respectively. Recent studies [37-40] have shown in severe COPD patients an high prevalence of normochromic normocytic anaemia type characteristic for diseases of chronic inflammation [37]. The low levels of haemoglobin appears to be due to resistance to the effects of erythropoietin, the concentration of which is elevated in these patients [41]. In the NOTT study patients with a high pulmonary vasculature resistance (PVR) and hematocrit showed highest mortality. After six months of treatment a significant reduction in PVR and hematocrit was seen but the longterm effects in terms of mortality is not known [6]. A recent retrospective [42] observational study evaluated the distribution and prognostic value of hematocrit in 2,524 patients with severe COPD who were receiving LTOT. Also keeping in mind the limitations of this study, it must be highlighted that lower hematocrit values at commencement of LTOT were associated with poor survival. Is not clear from the data reported whether comorbidities could have played a role on the haemoglobin level and consecutively on the prognosis. Celli et al [43] reported that among 207 patients studied for developing the BODE index, hematocrit was significantly lower in the COPD patients who died. How- ever, the prognostic value of low haemoglobin levels in severe COPD patients and the effects of oxygen therapy on the production of erythropoietin remain to be evaluated by prospective studies.

\section{$F E V_{1}$ (forced expiratory volume in 1 second)}

In a long term uncontrolled study of COPD patients in LTOT, Cooper [20] et al found that survival was clearly associated with the degree of bronchial obstruction but not with pulmonary artery pressure or total pulmonary vascular resistance. The benefit of LTOT was more pronounced in the subgroup of patients with $\mathrm{FEV}_{1}$ higher than $30 \%$ of predicted but the difference in survival disappeared abruptly at then years of treatment. At the moment there is few data to support the presumption that LTOT may influence the decline of $\mathrm{FEV}_{1}[44,45]$ and that $\mathrm{FEV}_{1}$ may be used to screen patient candidates for LTOT [5, 46, 47]. Considering the frequent comorbidities associated with COPD patients and the emerging role of $\mathrm{FEV}_{1}$ as an independent predictor of all-causes mortality [48] and as a strong risk factor for cardiovascular disease, stroke $[49,50]$, the effects of LTOT on COPD-specific end-point such as $\mathrm{FEV}_{1}$ appears meaningless.

\section{Neurophysiological performance}

It is well known that chronic hypoxemia may cause impaired judgment and progressive loss of cognitive performance in COPD patients $[1,51$, 52]. In chronic hypoxemic COPD patients LTOT after six months of treatment was found to improve general alertness, motor speed, and hand grip but not emotional status or the quality of life [53]. Another study reported a slight positive influence of neuropshychological function, cerebral blood flow velocity and autonomic function in COPD patients after 3 months of LTOT [54]. The sparse data on this topic warrants the use of oxygen for trying to improve COPD patient's mental function.

\section{Quality of life}

Health-related quality of life (HRQL), using disease-specific health measures, is an important clinical outcome for patients with severe COPD. HRQL represents a crucial end-point for symptomatic severe COPD patients, given that in these patients an improved HRQL may represent a better outcome than the possibility of living slightly longer. Even if quality of life (QoL) is impaired in COPD patients with hypoxemia, the effect of LTOT on HRQL remains unclear. QoL was not addressed in the MRC trial whereas in the NOTT trial it was measured by the Sickness Impact Profile (SIP), a questionnaire which measures the general health status. An improvement in QoL after 6 months of treatment both in patients receiving continuous oxygen and in those receiving only nocturnal oxygen as a whole was reported [6]. This result must be interpreted with caution giving that the 
analysis was not specific for the continuous oxygen group alone, did not include an untreated control group and furthermore the questionnaire used is not specific for patients with respiratory diseases $[55,56]$. There are very few longitudinal studies which have examined the effect of LTOT on QoL and this is mainly due, for ethical reasons, to the difficulty in incorporating into the study a placebo control group. It has been reported that the potential restriction of mobility imposed by the modality of oxygen delivery may be an important factor in modifying QoL. Okubadejo detected no significant changes in the QoL of patients with severe COPD receiving oxygen therapy through oxygen concentrators for 6 months [55]. Conversely, Andersson et al [57] showed improved HRQL in patients receiving liquid oxygen treatment and deterioration in those using concentrators in conjunction with small oxygen portable cylinders for mobility.

An important question is whether improvement in QoL can be related to the severity and chronicity of hypoxemia in COPD patients. Shortterm use of ambulatory oxygen has been reported to be associated with significant improvements in HRQL in COPD patients who do not fulfil criteria for LTOT but demonstrate significant exertional desaturation [58]. However the correction of oxygen desaturation was not predictive of acute response nor of a longer term improvement in HRQL in COPD patients. LTOT in patients with severe COPD fulfilling standard criteria was found associated with early improvements in HRQL with sustained or further response at 6 months [59]. Even though this outcome at the moment is not strongly supported by data, it is very important to stress that in a disease with very limited therapeutic options, the evaluation of HRQL is of paramount importance given that it is appreciated before any other clinical outcome.

\section{Effects of Oxygen Therapy on Sleep}

Non-apneic nocturnal oxyhaemoglobin desaturation (NOD) usually associated with REM sleep has been proposed as mechanism for pulmonary hypertension and cor pulmonale in COPD patients [60]. Higher mean PAP values were found in COPD patients with daytime $\mathrm{PaO}_{2}$ ranged from 60 to $70 \mathrm{mmHg}$ and nocturnal oxygen desaturation, defined as oxygen saturation below $90 \%$ for $>30 \%$ of the sleep time [61]. Nocturnal oxygen treatment did not show statistically significant impact on survival in COPD patients without severe daytime hypoxaemia with non apneic NOD $[62,63]$. Furthermore nocturnal oxygen was not found to modify the evolution of pulmonary haemodinamics in these patients [62].

Two important problems in COPD patients with chronic respiratory failure are the sleep quality with HRQL $[64,65]$ and the arbitrary increasing of oxygen flow during the night in order to prevent oxygen desaturation during sleep. LTOT improves HRQL [59] but the impact of LTOT on sleep quality remains controversial [66]. Poor sleep quality is probably multifactorial and its assessment is not simple because these patients are often advanced in age and have many co-morbidities which may influence the quality of sleep.

It has been reported [66] that most COPD patients on LTOT did not exhibit overnight desaturation despite not increasing their usual LTOT prescription overnight. These results challenge the current recommendations of routinely increasing the oxygen flow by $11 / \mathrm{min}$ during sleep to prevent overnight desaturation in all patients established on LTOT $[6,8,12,67]$. In summary, there are no clear benefits in treating patients with isolated nocturnal hypoxemia $[62,63,68]$, furthermore an overnight increase in $\mathrm{O}_{2}$ flow rate (originally recommended in NOTT) appears to be not appropriate [66] and it is necessary to reconsider this recommendation $[69,70]$. Larger prospective studies are required to clarify whether overnight oxygen lead to improved patient outcomes.

\section{Effects of Intermittent Oxygen Therapy on Exercise Induced Desaturation}

The role of intermittent oxygen during exercise in COPD patients who do not fulfil the conventional criteria for LTOT is arguable. Continuous oxygen therapy in this population has been shown to improve outcomes relating to endurance capacity but not to impact survival [27, 71-73].

Exercise desaturation has been shown previously to correlate with severity of pulmonary vascular disease in COPD patients with no or mild resting hypoxemia [74]. This characteristic was associated with less survival in COPD patients [75]. There is no evidence that the use of intermittent oxygen in exercise-induced desaturation should have a positive impact on pulmonary hypertension and survival, but it may improve quality of life [58] even if the data on benefits in HRQL is controversial $[55,64,76]$. Recently, the National Emphysema Treatment Trial (NETT) research group performed a retrospective analysis on the normoxemic patients in the medical arm of NETT trial [77]. They found that $21.4 \%$ of the 1215 NETT participants reported oxygen use outside of current guidelines despite having been recently enrolled in supervised pulmonary rehabilitation. Among this group of patients, who experienced desaturation during exercise had similar mortality even if they were using continuous, intermittent or no oxygen at all. These findings highlight the challenge of monitoring oxygen prescription and use.

A recent meta-analysis emphasises [78] that on the basis of actual evidence there are no consistent benefits for the use of oxygen-supplemented exercise training.

\section{Long Term Oxygen Therapy and Comorbidities}

Comorbidities are remarkably likely to affect both prognosis and health outcomes in COPD patients $[50,79,80]$. Clinical practice guidelines do not provide adequate guidance for patients in LTOT with complex chronic diseases. Although it 
is well known that the presence of cardiovascular co-morbidity increases the mortality risk for COPD patients [24], neither co-morbidity in general [81] nor cardiac co-morbidity in particular [82] was taken into account in any of the studies on LTOT in COPD. At the moment it is not known if continuous oxygen therapy reduces cardiovascular and/or metabolic mortality in hypoxemic COPD patients.

A recent retrospective study demonstrated that $\mathrm{BMI}<25 \mathrm{~kg}^{2} \cdot \mathrm{m}^{2}$ and the presence of comorbidities are predictors of all-cause and respiratory mortality in a cohort of COPD patients treated with LTOT [24]. It is important to clarify the true impact of LTOT on all-cause mortality in complex COPD patients.

Furthermore, it is becoming increasingly evident that combined and complex tools, such as health-status measurements (e.g. St George's Respiratory Questionnaire) $[83,84]$ and the BODE index [43], predict mortality better than $\mathrm{FEV}_{1}$ alone because they can reflect the complexity of underlying mechanisms related to different chronic disease associated with COPD.

As comorbidities, such as cardiovascular diseases, are often underdiagnosed and undertreated, it is important to search for their co-existence in hypoxemic COPD patients. In fact, due to a deficient diagnosis of comorbidities, the medical therapy cannot be optimised. As a consequence, chronic hypoxemia, which may be successfully treated with appropriate medications, becomes the objective of a questionable LTOT prescription.

The underlying mechanisms of chronic hypoxemia in COPD and CHF are different [85]. The value of $\mathrm{PO}_{2}$ in the arterial blood is regulated by intra-pulmonary and extra-pulmonary factors [85]. The former include: ventilation-perfusion mismatching, true shunt, and alveolar-capillary diffusion limitation. The latter consist of $\mathrm{FiO}_{2}$, minute ventilation, cardiac output and mixed venous $\mathrm{PO}_{2}$, as a result of peripheral oxygen uptake. In COPD, ventilation-perfusion mismatching without true shunt, i.e. an intrapulmonary factor, is the major mechanism of hypoxemia whereas in chronic heart failure $(\mathrm{CHF})$, the reduced cardiac output and the low mixed venous $\mathrm{PO}_{2}$, ie extrapulmonary factors, are the major determinants of hypoxemia. Administration of oxygen-enriched air increases alveolar $\mathrm{PO}_{2}$ and hence $\mathrm{PaO}_{2}$ when hypoxemia is caused by ventilation-perfusion mismatching. In fact, higher oxygen concentration reaches all the ventilating units. By contrast, the effect of oxygen administration is negligible when extrapulmonary factors, such as, for example, low cardiac output and low mixed $\mathrm{PvO}_{2}$, are the major causes of hypoxemia. In the patients with both COPD and CHF both the intra-pulmonary and the extra-pulmonary factors cause hypoxemia and both must be adequately treated [85]. The final value of $\mathrm{PaO}_{2}$ and the efficacy of oxygen administration depend upon their balance. Therefore, it is crucial, in these patients: first to recognise adequately the presence of the two conditions; second to provide the best possible medical treatment for both; and third to assess the effect of optimal therapy properly before the prescription of LTOT. Any different procedures can lead to incorrect LTOT prescription with unnecessary discomfort for the patients and waste of socioeconomic resources.

Actual guidelines provide adequate guidance for "pure" chronic obstructive pulmonary disease patients (i.e. those without any associated comorbidities) that probably explore therapeutic effects in a non-representative group of chronic obstructive pulmonary disease patients.

\section{Current guidelines criteria for LTOT prescription}

The LTOT indications, based from previous studies $[6,7]$, were established in a very selected and limited number of patients that are unlikely to represent the heterogeneity of the COPD population. A recent systemic Cochrane review on long-term oxygen therapy in COPD patients highlighted several problems with the patient selection and study design. The relatively small numbers and young age of patients, the lack of co-morbidities in most of these studies cast doubts concerning the applicability of the survival outcomes found in these studies to the current clinical situations [72]. Furthermore lack of exacerbations and hospitalisation data is also a limiting factor in interpreting the results of the studies included in this meta-analysis [72].

The actual current guidelines (table 2) are in agreement in recommending oxygen therapy for COPD patients with severe hypoxemia $\left(\mathrm{PaO}_{2}<55\right.$ $\mathrm{mmHg},<7.3 \mathrm{kPa}$ ), whereas some discrepancies are found in patients with moderate hypoxemia $\left(55<\mathrm{PaO}_{2}<60 \mathrm{mmHg}, 7.4<\mathrm{PaO}_{2}<8 \mathrm{kPa}\right)$ regarding the criteria which must be associated to $\mathrm{PaO}_{2}$ values [3-5, 8, 12].

The NICE guidelines report nocturnal desaturation greater than $30 \%$ of sleep time [5], whereas the AIPO guidelines report ischemic heart failure as adjunctive criterion for the prescription of LTOT [12]. The GOLD and the NICE guidelines do not recommend LTOT in COPD patients with $\mathrm{PaO}_{2} \geq 60 \mathrm{mmHg}$ (table 2), whereas ATS-ERS, Thoracic Society of Australia and New Zealand and AIPO guidelines do it [3-5, 8, 12].

These different indications induce different behaviours in the clinical practice according to the guidelines followed by doctors. For the social community the removal of inappropriate LTOT prescription leads to the saving of significant resources which can be better employed. In Italy, where the cost of treatment due to LTOT is estimated to approximately Euro 250,000,000/year, the AIPO OTLT guidelines are currently and extensively used. In these guidelines is recommended, without evidence, oxygen prescription when $\mathrm{PaO}_{2}$ values range from 56 to 59 in presence of chronic ischemic heart failure. This indication and that concerning the prescription of oxygen to patients with normoxia at rest and sleep or exerciserelated desaturation may be responsible of increased costs in prescribing LTOT on the basis of unproven indication. On the other hand we do not know if the lack of correction of exercise-related 
Table 2. - Comparison of guidelines for Long Term Oxygen Therapy in COPD

\begin{tabular}{|c|c|c|c|c|c|}
\hline HYPOXEMIA & ATS-ERS & GOLD & NCCC-NICE & $\begin{array}{l}\text { Thoracic Society of } \\
\text { Australia and New Zeland }\end{array}$ & AIP0 \\
\hline & ERJ 2004 (Ref. 4) & AJRCCM 2007 (Ref. 3) & Thorax 2004 (Ref.5) & MJA 2005 (Ref. 8) & Rass Pat App Resp 2004 (Ref. 12) \\
\hline Severe & $\mathrm{PaO}_{2}<55 \mathrm{mmHg}$ or $\mathrm{SpO}_{2} \leq 88 \%$ & $\mathrm{PaO}_{2} \leq 55 \mathrm{mmHg}$ or $\mathrm{SpO}_{2} \leq 88 \%$ & $\mathrm{PaO}_{2}<55 \mathrm{mmHg}$ & $\mathrm{PaO}_{2} \leq 55 \mathrm{mmHg}$ & $\mathrm{PaO}_{2}<55 \mathrm{mmHg}$ \\
\hline Moderate & $\begin{array}{l}\mathrm{PaO}_{2} \text { of } 55 \text { to } 59 \mathrm{mmHg} \\
\text { or } \mathrm{SpO}_{2} \text { of } 89 \% \text { and at least } \\
\text { one of the following criteria: } \\
\text { Cor pulmonale, } \\
\text { peripheral edema, } \\
\text { hematocrit }>55 \%\end{array}$ & $\begin{array}{l}\mathrm{PaO}_{2} \text { of } 55 \mathrm{to} 59 \mathrm{mmHg} \\
\text { or } \mathrm{SpO}_{2} \text { of } 89 \% \text { and at least } \\
\text { one of the following criteria: } \\
\text { pulmonary hypertension, } \\
\text { peripheral edema, } \\
\text { hematocrit }>55 \%\end{array}$ & $\begin{array}{l}\mathrm{PaO}_{2} \text { of } 55 \text { to } 59 \mathrm{mmHg} \\
\text { or } \mathrm{SpO}_{2} \text { of } 89 \% \text { and at least } \\
\text { one of the following criteria: } \\
\text { pulmonary hypertension, } \\
\text { peripheral edema, } \\
\text { secondary polycythemia, } \\
\text { nocturnal desaturation } \\
>30 \% \text { of sleep time }\end{array}$ & $\begin{array}{l}\mathrm{PaO}_{2} \text { of } 56 \mathrm{mmHg} \text { to } 59 \\
\text { and there is evidence } \\
\text { of hypoxic organ damage } \\
\text { (right hearth failure, } \\
\text { pulmonary hypertension, } \\
\text { peripheral edema, } \\
\text { secondary polycythaemia) }\end{array}$ & $\begin{array}{l}\mathrm{PaO}_{2} \text { of } 55 \mathrm{mmHg} \text { to } 60 \\
\text { and at least one of the } \\
\text { following criteria: } \\
\text { hematocrit }>55 \% \text {, } \\
\text { signs of pulmonary } \\
\text { hypertension, } \\
\text { signs of hypoxia } \\
\text { (peripheral edema of right heart } \\
\text { failure, mental decline) } \\
\text { ischemic heart failure }\end{array}$ \\
\hline None & $\begin{array}{l}* \mathrm{PaO}_{2} \geq 60 \mathrm{mmHg} \text { or } \mathrm{SpO}_{2}>90 \% \\
\text { with severe nocturnal } \\
\text { desaturation and lung-related } \\
\text { dyspnea responsive to oxygen }\end{array}$ & No raccomandation & No raccomandation & $\begin{array}{l}\text { * Nocturnal oxygen } \\
\text { may be indicate: } \\
\text { desaturation }\left(\mathrm{SpO}_{2} \leq 88 \%\right) \\
>30 \% \text { of sleep time or in } \\
\text { presence of hypoxia-related } \\
\text { sequelae }\end{array}$ & $\begin{array}{l}\text { * Intermittent oxygen } \\
\text { may be indicate: } \\
\text { desaturation }\left(\mathrm{SpO}_{2}<90 \%\right) \\
>30 \% \text { of sleep time or in } \\
\text { presence of exercise-related } \\
\text { desaturation }\end{array}$ \\
\hline
\end{tabular}

and nocturnal desaturation with intermittent oxygen administration may have long term prognostic implication.

\section{Conclusion}

Increased life expectancy in the general population will lead into an increase in the numbers of patients surviving beyond the age of 70 with chronic diseases, like COPD. Therefore, reducing the morbidity and mortality in patients with advanced lung disease will take on additional significance.

LTOT is one of the few interventions that improves survival in COPD and it is widely used also in other clinical conditions associated with hypoxemia without any prove of evidence. Progress with LTOT may come from a more accurate definition of those groups of patients most likely to benefit, and a better definition of predictors of benefit other than survival is important.

Current guidelines presume that everyone who meets the inclusion criteria for the NOTT or MRC trial $[6,7]$ will benefit of LTOT and everyone who fails to meet these inclusion criteria will not benefit $[29,86]$. This assumption is based only on the level of arterial oxygen values established by NOTT and MRC investigators. The usefulness of other measures of disease severity for predicting who will and will not benefit from LTOT has not been systematically addressed in clinical trails. Nevertheless, the high overall cost of LTOT argues that it should be prescribed only for patients in whom there is a reasonable expectation of clinical benefit.

The increasing evidence that active treatment of comorbidities may reduce morbidity and mor- tality in patients with COPD [87] suggests the urgent need for randomised clinical trials that hopefully will provide evidence for more comprehensive clinical guidelines for these patients. If comorbidity, in particular cardiovascular co-morbidity and $\mathrm{CHF}$, are not appropriately considered, the medical therapy may be insufficient $[81,82]$ and the positive effect of LTOT overestimated for the lack of adequate pharmacological treatment. Clearly, a reassessment of the evidence supporting the extensive prescription of LTOT is reasonable and needed, particularly for old, fragile patients with chronic co-morbidities. The current guidelines with their misleading messages should be the starting point for future studies. Open fields that future research should address include: optimal timing and duration of oxygen therapy during rest, exercise and sleep, ways of identifying COPD patients and relative comorbidities who are most likely to benefit and ways of improving patient compliance. All of these topics should provide more appropriate guidance regarding LTOT prescription in clinical practice.

\section{References}

1. Kim V, Benditt JO, Wise RA, Sharafkhaneh. Oxygen theraphy in Chronic Obstructive Pulmonary Disease. Proc Am Thorac Soc 2008; 5: 513-518.

2. O' Donohue WJ, Plummer AL. Magnitude of usage and cost of home oxygen therapy in the United States. Chest 1995; 107: 301-302.

3. Rabe KF, Hurd S, Anzueto A, et al. Global strategy for the diagnosis, management and prevention of COPD, 2006 update. Am J Respir Crit Care Med 2007; 176: 532-555.

4. Celli BR, MacNee W. Standards for the diagnosis and treatment of patients with COPD: a summary of the 
ATS/ERS position paper. Eur Respir J 2004; 23: 932946.

5. National Collaborating Centre for Chronic Conditions. Chronic obstructive pulmonary disease: national clinical guidelines on management of chronic obstructive pulmonary disease in adults in primary and secondary care. Thorax 2004; 59: 1-232.

6. Continuous or nocturnal oxygen therapy in hypoxemic chronic obstructive lung disease: a clinical trial. Nocturnal Oxygen Therapy Trial Group. Ann Intern Med 1980; 93: 391.

7. Long term domiciliary oxygen therapy in chronic hypoxic cor pulmonale complicating chronic bronchitis and emphysema. Report of the Medical Research Council Working Party. Lancet 1981; 1: 681-686.

8. McDonald CF, Crockett AJ, Young IH. Adult domiciliary oxygen therapy. Position Statement of the Thoracic Society of Australian and New Zealand. MJA 2005; 182: 621-626.

9. Levi-Valensi P, Weitzenblum E, Pedinelli JL, Racineux JL, Duwoos H. Three month follow up of arterial blood gas determination in candidates for LTOT. Am Rev Respir Dis 1986; 133: 547-551.

10. Eaton TE, Grey C, Garret JE. An evaluation of shortterm oxygen therapy: the prescription of oxygen to patient with chronic lung disease hypoxic at discharge from hospital. Respir Med 2001; 95: 582-587.

11. Guyatt GH, Nonoyama M, Lacchetti C, et al. A randomized trial of strategies for assessing eligibility for long-term domiciliary oxygen therapy. Am J Respir Crit Care Med 2005; 172: 573-580.

12. Murgia A, Scano G, Palange P, et al. Gruppo di Studio Riabilitazione Respiratoria. Linee Guida per l'Ossigenoterapia a Lungo Termine. Aggiornamento anno 2004. Rassegna di Patologia dell'Apparato Respiratorio 2004; 19: 206-219.

13. Mannino DM, Braman. The Epidemiology and Economics of Chronic Obstructive Pulmonary Disease. Proc Am Thorac Soc 2007; 4: 502-506.

14. Koleva D, Motterlini N, Banfi P, Garattini L, on behalf of the Study Group BIC. Healthcare costs of COPD in Italian referral centres: a prospective study. Respir Med 2007; 101: 2312-2320.

15. Timms RM, Khaja FU, Williams GW, Nocturnal Oxygen Therapy Trial Group. Hemodynamic response to oxygen therapy in chronic obstructive pulmonary disease. Ann Intern Med 1985; 102: 29-36.

16. Weitzenblum E, Sautegeau A, Ehrhart M, Mammosser M, Pelletier A. Long-term oxygen therapy can reverse the progression of pulmonary hypertension in patients with chronic obstructive pulmonary disease. Am Rev Respir Dis 1985; 131: 493-8.

17. Tarpy SP, Celli BR. Long-term oxygen therapy. New Engl J Med 1995; 333: 710-714.

18. Strom K. Survival of patients with chronic obstructive pulmonary disease receiving long-term domiciliary oxygen therapy. Am Rev Respir Dis 1993; 147: 585591.

19. Dubois P, Jamart J, Machiels J, Smeets F, Lulling J. Prognosis of severely hypoxemic patients receiving long-term oxygen therapy. Chest 1994; 105: 469-474.

20. Cooper CB, Waterhouse J, Howard P. Twelve year clinical study of patients with hypoxic cor pulmonale given long term domiciliary oxygen therapy. Thorax 1987; 42: $105-110$.

21. Oswald-Mammosser M, Weitzenblum E, Quoix E, et al. Prognostic factors in COPD patients receiving longterm oxygen therapy: importance of pulmonary artery pressure. Chest 1995; 107: 1193-1198.

22. Aida A, Miyamoto K, Nishimura M, Aiba M, Kira S, Kawakami Y, and the Respiratory Failure Research Group in Japan. Prognostic value of hypercapnia in pa- tients with chronic respiratory failure during long-term Oxygen therapy. Am J Respir Crit Care Med 1998; 158: 188-193.

23. Foucher P, Baudouin N, Merati M, et al. Relative survival analysis of 252 patients with COPD receiving long term Oxygen therapy. Chest 1998; 113; 15801587.

24. Marti S, Munoz X, Rios J, Morell F, Ferrer J. Body weight and comorbidity predict mortality in COPD patients treated with oxygen therapy. Eur Respir J 2006; 27: 689 .

25. Neff TA, Petty TL. Long-term continuous oxygen therapy in chronic airway obstruction: mortality in relationship to cor pulmonale, hypoxia and hypercapnia. Ann Intern Med 1970; 72: 621-6.

26. Stark RD, Finnegan P, Bishop JM. Long-term domiciliary oxygen in chronic bronchitis with pulmonary hypertension. BMJ 1973; 3: 467-70.

27. Gorecka D, Gorselak K, Sliwinski P, Tobiasz M, Zielinski J. Effect of long term oxygen therapy on survival in patients with chronic obstructive pulmonary disease with moderate hypoxaemia. Thorax 1997; 52: 674- 679.

28. Selinger SR, Kennedy TP, Buescher P, et al. Effects of removing oxygen from patients with chronic obstructive pulmonary disease. Am Rev Respir Dis 1987; 136: 85-91.

29. Croxton TL, Bailey WC for the NHLBI Working Group on Long-term Oxygen Treatment in COPD. Long-term Oxygen Treatment in Chronic Obstructive Pulmonary Disease: Recommendations for Future Research. An NHLBI Workshop Report. Am J Respir Crit Care Med 2006; 174: 373-378.

30. Weitzenblum E, Loiseau A, Hirth C, Mirhom R, Rasaholinjanahary J. Course of pulmonary hemodynamics in patients with chronic obstructive pulmonary disease. Chest 1979; 75: 656-662.

31. Incalzi RA, Fuso L, De Rosa M, et al. Electrocardiographic signs of chronic cor pulmonale: a negative prognostic finding in chronic obstructive pulmonary disease. Circulation 1999; 99: 1600-5.

32. Kessler R, Faller M, Fourgaut G, Mennecier B, Weitzenblum E. Predictive factors of hospitalization for acute exacerbation in a series of 64 patients with chronic obstructive pulmonary disease. Am J Respir Crit Care Med 1999; 159: 158-164.

33. Chaouat A, Naeije R, Weitzenblum E. Pulmonary hypertension in COPD. Eur Respir $J$ 2008; 32: 13711385.

34. Elwing J, Panos RJ. Pulmonary hypertension associated with COPD. Int J Chron Obstruct Pulmon Dis 2008: 3: 55-70.

35. Chaouat A, Bugnet AS, Kadaoui N, et al. Severe pulmonary hypertension and chronic obstructive pulmonary disease. Am J Respir Crit Care Med 2005; 172: 189-194.

36. Vanbank K, Ziesche R, Higenbottam TW, et al. Controlled prospective randomised trial on the effects on pulmonary haemodynamics of the ambulatory long term use of nitric oxide and oxygen in patients with severe COPD. Thorax 2003; 58: 289-293.

37. Barnes PJ, Celli BR. Systemic manifestations and comorbidities of COPD. Eur Respir J 2009; 33: 11651185.

38. John M, Lange A, Hoerning S, Witt C, Anker SD. Prevalence of anemia in chronic obstructive pulmonary disease: comparison to other chronic diseases. Int J Cardiol 2006; 111: 365-370.

39. Cote C, Zilberberg MD, Mody SH, Dordelly LJ, Celli B. Haemoglobin level and its clinical impact in a cohort of patients with COPD. Eur Respir J 2007; 29: 923929. 
40. Shorr AF, Doyle J, Stern L, Dolgister M, Zilberberg MD. Anemia in chronic obstructive pulmonary disease: epidemiology and economic implications. Curr Med Res Opin 2008; 24: 1123-1130.

41. John M, Hoerning S, Doehner W, Okonko DD, Witt C, Anker SD. Anemia and inflammation in COPD. Chest 2005; 127: 825-829.

42. Chambellan A, Chailleux E, Similowski T, and the ANTADIR Observatory Group. Prognostic value of the hematocrit in patients with severe COPD receiving long-term Oxygen therapy Chest 2005; 128; 12011208.

43. Celli BR, Cote CG, Marin JM, et al. The body-mass index, airflow obstruction, dyspnea, and exercise capacity index in chronic obstructive pulmonary disease. $N$ Engl J Med 2004; 350: 1005-1012.

44. Weitzenblum E, Oswald M, Apprill M, Ratomaharo J, Kessler R. Evolution of physiological variables in patients with chronic obstructive pulmonary disease before and during long-term oxygen therapy. Respiration 1991; 58: 126-31.

45. Gluskowski J, Jedrzejewska-Makowska, Hawrylkiewicz I, VetunB, Zielinski J. Effects of prolonged oxygen therapy on pulmonary hypertension and blood viscosity in patients with advanced cor pulmonale. Respiration 1983; 44: 177-83.

46. Global initiative for chronic obstructive lung disease. A collaborative project of the National Heart, Lung, and Blood Institute, National Institutes of Health, and the World Health Organization. Bethesda (MD): National Institutes of Health, National Heart, Lung, and Blood Institute; 2007. Available from: www.goldcopd.org (accessed 2008Oct 14).

47. Lim S, MacRae KD, Seed WA, Roberts CM. The value of forced expiratory volume in $1 \mathrm{~s}$ in screening subjects with stable COPD for $\mathrm{PaO}_{2}<7.3 \mathrm{kPa}$ qualifying for longterm oxygen therapy Respir Med 1998; 92: 1122-6.

48. Schunemann HJ, Dorn J, Grant BJ, Winkelstein W Jr, Trevisan M. Pulmonary function is a long-term predictor of mortality in the general population: 29-year follow-up of the buffalo health study. Chest 2000; 118: 656-664.

49. Cook NR, Hebert PR, Satterfield S, et al. lung function, and mortality from cardiovascular disease among the elderly. Am J Epidemiol 1994; 139: 1066-1076.

50. Sin DD, Anthonisen NR, Soriano JB, Agusti AG. Mortality in COPD: role of comorbidities. Eur Resp J 2006; 1245-1257.

51. Grant I, Heaton RK, McSweeny AJ, Adams KM, Timms RM. Neuropsychologic findings in hypoxemic chronic obstructive pulmonary disease. Arch Intern Med 1982; 142: 1470-6.

52. Prigatano GP, Parsons OA, Wright E, Levin DC, Hawryluk G. Neuropsychological test performance in mildly hypoxemic patients with chronic obstructive pulmonary disease. J Consult Clin Psychol 1983; 51: 108-16.

53. Heaton RK, Grant I, McSweeny AJ, Adams KM, Petty TL. Psychologic effects of continuous and nocturnal oxygen therapy in hypoxemic chronic obstructive pulmonary disease. Arch Intern Med 1983; 143: 1941-7.

54. Hjalmarsen A, Waterloo K, Dahl A, Jorde R, Viitanen $\mathrm{M}$. Effect of long-term oxygen therapy on cognitive and neurological dysfunction in chronic obstructive pulmonary disease. Eur Neurol 1999; 42: 27-35.

55. Okubadejo A, Jones P, Wedzicha J. Quality of life in patients with chronic obstructive pulmonary disease and severe hypoxaemia. Thorax 1996; 51: 44-7.

56. Carone M, Bertolotti G, Anchisi F, Zotti AM, Donner $\mathrm{CF}$, Jones PW on behalf of the "Quality of Life in Chronic Respiratory Failure Group". Analysis of factors that characterize health impairment in patients with chronic respiratory failure. Eur Respir J 1999; 13: 1293-1300.

57. Andersson A, Strom K, Brodin H, et al. Domiciliary liquid oxygen versus concentrator treatment in chronic hypoxaemia: a cost-utility analysis. Eur Respir J 1998; 12: 1284-9.

58. Eaton TE, Garret JE, Young P, et al. Ambulatory oxygen improves quality of life of COPD patients: a randomized controlled study. Eur Resp J 2002; 20: 306-312.

59. Eaton T, Lewis C, Young P, Kennedy Y, Garrett JE, Kolbe J. Long-term oxygen therapy improves health-related quality of life. Respir Med 2004; 98: 285-293.

60. Fletcher EC, Miller J, Divine GW, Fletcher JG, Miller T. Nocturnal oxyhemoglobin desaturation in COPD patients with arterial oxygen tensions above $60 \mathrm{mmHg}$. Chest 1987; 92: 604-608.

61. Levi-Valensi P, Weitzenblum E, Rida Z, et al. Sleep-related oxygen desaturation and daytime pulmonary haemodynamics in COPD patients. Eur Respir J 1992; 5: 301-307.

62. Chaouat A, Weitzenblum E, Kessler R, et al. A randomized trial of nocturnal oxygen therapy in chronic obstructive pulmonary disease patients. Eur Respir J 1999; 14: 1002-1008.

63. Fletcher EC, Donner CF, Midgren B, et al. Survival in COPD patients with a daytime $\mathrm{PaO}_{2}$ greater than 60 $\mathrm{mmHg}$ with and without nocturnal oxyhemoglobin desaturation. Chest 1992; 101; 649-655.

64. Okubadejo A, Paul E, Jones P, Wedzicha J. Does longterm oxygen therapy affect quality of life in patients with chronic obstructive pulmonary disease and severe hypoxaemia? Eur Respir J 1996; 9: 2335- 2339.

65. Cormick W, Olson L, Hensley M, Saunders NA. Nocturnal hypoxaemia and quality of sleep in patients with chronic obstructive lung disease. Thorax 1986; 41: 846-54.

66. Nisbet M, Eaton T, Lewis C, Fergusson W, Kolbe J. Overnight prescription in long term oxygen therapy: time to reconsider the guidelines? Thorax 2006; 61: 779-782.

67. ATS Statement. Standards for the diagnosis and care of patients with chronic obstructive pulmonary disease. Am J Resp Crit Care Med 1995; 152: S77-S120.

68. Chaouat A, Weitzenblum E, Kessler R, et al. Sleep related $\mathrm{O}_{2}$ desaturation and daytime pulmonary haemodynamics in COPD patients with mild hypoxaemia. Eur Resp J 1997; 10: 1730-1735.

69. Calverley PA, Calverley PMA. Drugs (including oxygen) in severe COPD. Eur Resp J 2008; 31: 1114-1124.

70. Guell Rous R. Long-term oxygen therapy: are we prescribing appropriately? Int J Chron Obstruct Pulmon Dis 2008; 3: 231-7.

71. Haidl P, Clement C, Wiese C, Dellweg D, Kohler D. Long-term oxygen therapy stops the natural decline of endurance in COPD patients with reversible hypercapnia. Respiration 2004; 71: 342-347.

72. Cranston JM, Crockett AJ, Moss JR, Alpers JH. Domiciliary oxygen for chronic obstructive pulmonary disease. Cochrane Database of Systematic Reviews 2005; Issue 4: CD001744. DOI: 10.1002/14651858.CD001744.pub2.

73. National Emphysema Treatment Trial Research group. A randomized trial comparing lung-volume-reduction surgery with medical therapy for severe emphysema. $N$ Engl J Med 2003; 348: 2059-2073.

74. Christensen CC, Ryg MS, Edvardsen A, Skjønsberg $\mathrm{OH}$. Relationship between exercise desaturation and pulmonary haemodinamics in COPD patients. Eur Respir J 2004; 24: 580-586.

75. Weitzenblum E, Hirth C, Ducolone A, Mirhom R, Rasaholinjanahary J, Ehrhart M. Prognostic value of pulmonary artery pressure in chronic obstructive pulmonary disease. Thorax 1981; 36: 752-758. 
76. Lacasse Y, Lecours R, Pelletier C, Begin R, Maltais F. Randomised trial of ambulatory oxygen in oxygen-dependent COPD. Eur Respir J 2005; 25: 1032-1038.

77. Drummond MB, Blackford AL, Benditt JO, et al, for the NETT Investigators. Continuous Oxygen Use in Nonhypoxemic Emphysema Patients Identifies a HighRisk Subset of Patients. Retrospective Analysis of the National Emphysema Treatment Trial Chest 2008; 134; 497-506.

78. Nonoyama M, Brooks D, Lacasse Y, Guyatt GH, Goldstein R. Oxygen therapy during exercise training in chronic obstructive pulmonary disease. Cochrane Database of Systematic Reviews 2007, Issue 2. Art. No: CD005372. DOI: 10.1002/14651858.CD005372.pub2.

79. Mannino DM, Thorn D, Swensen A, Holguin F. Prevalence and outcomes of diabetes, hypertension and cardiovascular disease in COPD. Eur Respir J 2008; 32: 962-969.

80. Holguin F, Folch E, Redd SC, Mannino DM. Comorbidity and mortality in COPD-related hospitalizations in the United States, 1979 to 2001. Chest 2005; 128: 2005-2011.

81. Boyd CM, Darer J, Boult C, Fried LP, Boult L, Wu AW. Clinical Practice Guidelines and quality of care for old- er patients with multiple comorbid diseases: implications for pay for performance. JAMA 2005 294: 716-24.

82. Le Jemtel TH, Padeletti M, Jelic S. Diagnostic and Therapeutic Challenges in Patients With Coexistent Chronic Obstructive Pulmonary Disease and Chronic Heart Failure. J Am Coll Cardiol 2007; 49: 171-80.

83. Antonelli-Incalzi R, Imperiale $\mathrm{C}$, Bellia V, et al. Do GOLD stages of COPD severity really correspond to differences in health status? Eur Respir J 2003; 22: 444-449.

84. Ferrer M, Alonso J, Morera J, et al. Chronic obstructive pulmonary disease stage and health-related quality of life. The Quality of Life of Chronic Obstructive Pulmonary Disease Study Group. Ann Intern Med 1997; 127: 1072-1079.

85. Rodriguez-Roisin R, Roca J. Mechanisms of hypoxemia. Intensive Care Med 2005; 31: 1017-1019.

86. O'Reilly P, Bailey. Long-term continuous oxygen treatment in chronic obstructive pulmonary disease: proper use, benefits and unresolved issues. Curr Opin Pulm Med 2007; 13: 120-124.

87. Luppi F, Franco F, Beghè B and Fabbri LM. Treatment of chronic obstructive pulmonary disease and its comorbidities. Proc Am Thorac Soc 2008; 5: 848-856.

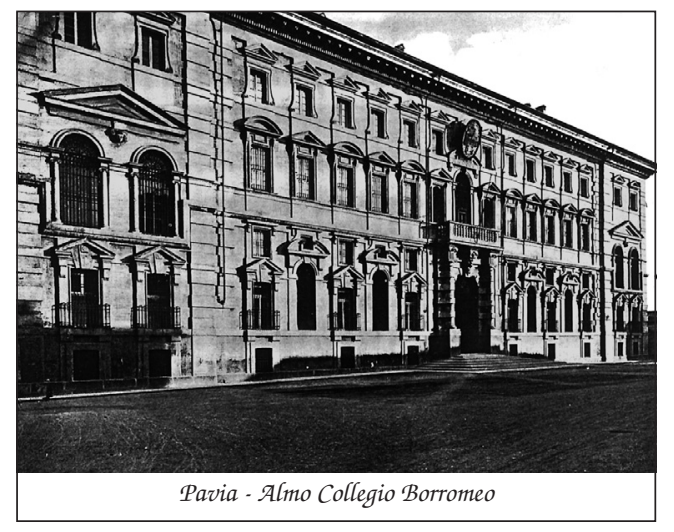

